\title{
Elmayı en çok kim isırıyor? Akıllı telefon bağımlılığını etkileyen sosyoekonomik faktörlerin tespiti
} Araştırma Makalesi/Research Article

\author{
Hasan Giray ANKARA, (D) Büşra TEKİN, (D) Esma ÖZ \\ Sağlık Yönetimi Bölümü, Sağlık Bilimleri Üniversitesi, İstanbul, Türkiye \\ hg.ankara@sbu.edu.tr, busra.kopmaz@ sbu.edu.tr, esma.oz@ sbu.edu.tr \\ (Geliş/Received:17.02.2020; Kabul/Accepted:07.06.2020) \\ DOI: $10.17671 /$ gazibtd. 690046
}

\begin{abstract}
$\ddot{O}_{z}$ et- Bu çalışma akıllı telefon bağımlılı̆ı̆ını sosyoekonomik belirleyicilerini araştırmaktadır. Çalışmanın odağı akıllı telefonların konuşma amaçlı kullanımından ziyade artan işlevsellikleri dolayısıyla telefonla konuşma amacı dışındaki (ikincil amaçlar için) kullanımlarıdır. Çalışmanın karakteristik özelliği çalışma kapsamında elde edilen akıllı telefon kullanım sürelerinin doğrudan kullandığı akıllı telefondan temin edilmesidir. Bu bağlamda, çalışma kapsamında, beş hafta boyunca 144 gönüllü katılımcıdan akıllı telefonlarının kullanım sürelerini gösteren ekran görüntüleri alınmıştır. Elde edilen veriler ile çok değişkenli (lineer) regresyon yöntemi kullanılarak sosyoekonomik faktörlerin akıllı telefon kullanımına etkileri tespit edilmiştir. Buna göre kişinin cinsiyeti, medeni hali, eğitim seviyesi ve gelir seviyesi kişinin akıllı telefon kullanım alışkanlığı üzerine önemli bir etkiye sahiptir. Erkeklerin ve kadınların akıllı telefon kullanım alışkanlıkları arasında ciddi farklılıklar bulunmuştur. Erkekler kadınlara kıyasla önemli ölçüde daha fazla akıllı telefon kullanmaktadır. Öte yandan evli olan bireyler ise evli olmayan bireylere kıyasla daha düşük akıllı telefon kullanımına sahiptirler. Üniversite mezunları, kendilerinden daha düşük eğitim seviyesine sahip bireylere göre daha fazla akıllı telefon kullanmaktadır. Bununla birlikte, en yüksek gelir kategorisinde bulunan bireylerin akıllı telefon kullanımı kendilerinden daha düşük gelir seviyelerindeki bireylerin tümüne kıyasla daha yüksektir. Son olarak, kişilerin yaşının, çalışma durumlarının ve toplu taşıma kullanma durumlarının akıllı telefon kullanım alışkanlıklarına belirgin bir etkisi saptanamamıştır.
\end{abstract}

Anahtar Kelimeler - akıllı telefon, akıllı telefon kullanımı, akıllı telefon bağımlılığı, ikincil kullanım, akıllı telefonların ikincil kullanımı.

\section{Who Bites The Apple Most? Determining the socioeconomic factors affecting smartphone addiction}

\begin{abstract}
This study investigates the socioeconomic determinants of smart phone addiction. The focus of the study is on the use of smartphones for secondary purposes as they have become more functional rather than the use of conversational purposes. The distinctive characteristic of the study is obtaining the data of smartphone usage from individuals' smartphones directly. In this regard, the screenshots illustrating the details of their use of smartphones have been obtained from 144 voluntary participants for five weeks. Once this data has been obtained, the effects of socioeconomic factors on the usage of smartphones have been identified using multiple (linear) regression. Accordingly, gender, marital status and the levels of education and income have considerable effects on the use of smartphones. Significant differences have been found between smartphone using habits of men and women. The use of smartphones is dramatically more among men in comparison to women. Besides, married individuals have lesser use of smartphones than their non-married counterparts. University graduates have higher use of smartphones compared to the individuals with lower levels of education. Additionally, the highest income group has higher use of smartphones compared to all other income groups. Finally, age, occupational status and the use of public transport do not have statistically significant effects on the use of smartphones.
\end{abstract}

Keywords - smartphone, smartphone usage, smartphone addiction, secondary use of smartphones, secondary use 


\section{GİRIŞ (INTRODUCTION)}

Teknolojinin gelişmesiyle birlikte geleneksel telefonlar dönüşüme uğramış ve işlevsellik kazanarak telefonla konuşmanın dışında birçok ihtiyacımızı karşılar hale gelmiştir [36]. Bankacılık işlemlerinden navigasyona, sosyal iletişimden eğlenceye kadar çeşitli birçok alanda kullanılan akıllı telefonlar artık günlük yaşantının bir vazgeçilmezi olmuştur [24, 8]. Artan işlevsellikleri ile hayatı daha kolay bir hale getiren akıllı telefonların hem kullanıcı sayıları hem de kullanım süreleri önemli bir artış göstermiştir [11]. Şu an dünya çapında yaklaşık dört milyar kişi akıllı telefon kullanmakta ve günlük ihtiyaçlarının büyük bir kısmını akıllı telefon kullanarak karşılamaktadır [37].

Akıllı telefonların, insanoğlunun ihtiyaç duyduğu birçok alanda kolaylıklar sağlaması fazla kullanımdan doğan sorunları da beraberinde getirmiştir. Öyle ki; bugün akıllı telefon bağımlılığı en yaygın bağımlılık türlerinden biri haline gelmiştir [35].

$\mathrm{Bu}$ çalışma akıllı telefonların artan işlevsellikleri dolayısıyla ortaya çıkan akıllı telefon bağımlılığının sosyoekonomik belirleyicilerini araştırmaktadır. Bir başka deyişle, bu çalışma, akıllı telefonların telefon ile konuşma amacı (birincil kullanım) dışındaki amaçlar için kullanımlarına (ikincil kullanım) ve akıllı telefon bağımlılığına etki eden sosyal, demografik ve ekonomik faktörleri incelemektedir. Çalışma akıllı telefonların birincil kullanımına dair (akıllı telefonların konuşma amaçlı kullanımı) herhangi bir şey söylememektedir. Dolayısıyla bu çalışma boyunca 'akıllı telefon kullanımı' söylemi ile kastedilen kullanım, akıllı telefonların telefon ile konuşmak dışındaki amaçlar için (dolayısıyla ikincil) kullanımıdır.

Çalışmanın karakteristik özelliği, çalışma kapsamında elde edilen akıllı telefon (ikincil) kullanımının kişilerin doğrudan kullandığı akıllı telefondan temin edilmesidir. $\mathrm{Bu}$ bağlamda beş hafta boyunca gönüllü katılımcılardan akıllı telefonlarının kullanım sürelerini gösteren ekran görüntüleri alınmıştır. Akıllı telefon kullanım süresini izleyen özelliğin sadece Apple marka telefonlarda olması dolayısıyla çalışmanın örneklemi sadece Apple marka akıllı telefon kullanıcıları ile sınırlı tutulmuştur.

Çalışmada elde edilen bulguların sağlamlığını sınamak amacıyla, ekran görüntüleri ile tespit edilen kullanım sürelerine ilave olarak akıllı telefonların bağımlılığını ölçen; Kwon ve arkadaşları [18] tarafından geliştirilen, Demirci ve arkadaşları [6] tarafından da Türkçe' ye uyarlanarak geçerlilik ve güvenilirliği yapılan 33 maddelik akıllı telefon bağımlılık ölçeği uygulanmıştır.

Elde edilen veriler ekonometrik yazılım (STATA) aracılı̆̆ ile işlenerek sosyoekonomik model oluşturulmuş ve çok değişkenli (lineer) regresyon yöntemi ile sosyoekonomik faktörlerin akıllı telefon kullanım süresi ile akıllı telefon bağımlılık skorları üzerindeki etkileri tespit edilmiştir. Buna göre erkeklerin ve kadınların akıllı telefon kullanım alışkanlıkları arasında ciddi farklılıklar bulunmuştur.
Erkekler kadınlara kıyasla önemli ölçüde daha fazla akıllı telefon kullanmaktadır. Öte yandan evli olan bireyler ise evli olmayan bireylere kıyasla daha düşük akıllı telefon kullanımına sahiptirler. Üniversite mezunları, kendilerinden daha düşük eğitim seviyesine sahip bireylere göre daha fazla akıllı telefon kullanmaktadır. Bununla birlikte, en yüksek gelir kategorisinde bulunan bireylerin akıllı telefon kullanımı kendilerinden daha düşük gelir seviyelerindeki bireylerin tümüne kiyasla daha yüksektir. Son olarak, kişilerin yaşının (istatistiksel olarak anlamlı olmasına rağmen), çalışma durumlarının ve toplu taşıma kullanma durumlarının akıllı telefon kullanım alışkanlıklarına belirgin bir etkisi saptanamamıştır.

\section{LITERATÜR (LITERATURE)}

Dünya üzerinde yaklaşık dört milyar akıllı telefon kullanıcısı bulunmaktadır [37] ki bu rakam dünya üzerinde yaşayan insanların aşağı yukarı yarısının akıllı telefon kullandığı anlamına gelmektedir [9]. Toplam nüfusunun \%73'ünün akıllı telefon kullandığı Türkiye [37] akıllı telefon kullanımında dünya ortalamasının oldukça üzerinde seyretmekte ve en fazla akıllı telefon kullanımına sahip ülkeler arasında yer almaktadır [37]. Bu nedenle Türkiye'de akıllı telefonların kullanımının ve akıllı telefon kullanımına etki eden faktörlerin incelenmesi ilgi çekicidir ve literatür için önem arz etmektedir.

Akıllı telefonların fazla kullanımları, başta akıllı telefon bağımlılığı olmak üzere bir takım olumsuz sonuçlara sebep olmaktadır [36]. Akıllı telefon bağımlılığı, teknolojik bağımlılık çerçevesinde yer almakla beraber; akıllı telefonların kontrolsüz kullanımı olarak tanımlanmaktadır [11]. Zira bağımlılık kelime anlamı olarak, bireyin bir insan, alışkanlık veya maddeye olumsuz etkilerine rağmen kendini adama ve kontrol edememe durumu olarak ifade edilmektedir [31, 34].

Akıllı telefon bağımlılığının fiziksel ve psikolojik sorunlara yol açtı ̆̆ halihazırda gerçekleştirilen çalışmalarda tespit edilmiştir. Aşırı telefon kullanımının sebep olduğu fiziksel sorunlar arasında karpal tünel sendromu ve diğer bilek rahatsızlıkları [22, 29, 12], öne doğru eğilmekten kaynaklanan duruş bozukluğu [21 27], baş ve boyun ağrıları $[27,15,16,33]$ bulunmaktadır. Öte yandan, depresyon [38, 39], artan endişe ve stres [5, 30], uyku ve yeme bozuklukları [4, 23, 31], enerji, motivasyon ve özgüven eksiklikleri [20] ise aşırı telefon kullanımının sebep olduğu psikolojik sorunlar arasındadır.

Kişilerin sosyoekonomik karakterleri ile akı1lı telefon kullanımları arasındaki ilişkiyi inceleyen çeşitli çalışma örnekleri bulunmaktadır. Söz konusu örneklere göre, sosyoekonomik faktörlerin akıllı telefon kullanımında belirleyici olup olmadığı hususunda bir belirsizlik bulunmaktadır; zira literatürde, sosyoekonomik faktörlerin akıllı telefon kullanımına etkisi olduğunu belirten çalışmalar kadar sosyoekonomik faktörlerin akıllı telefon kullanımına belirgin bir etkisi olmadığını iddia eden çalışmalara da rastlamak mümkündür. Örneğin, Junco ve arkadaşları [14], Randler ve arkadaşları [28] ile Kim ve arkadaşları [17] kadınların erkeklere oranla daha fazla 
akıllı telefon kullandığını; Aljooma ve arkadaşları [2] ise erkeklerin kadınlara oranla daha fazla akıllı telefon kullandığını belirtirken, Kwon ve arkadaşları [18], Ünal [33], Kuyucu [19], Mert ve Özdemir [25] çalışmalarında akıllı telefon kullanımının cinsiyetle ilişkili olmadığı sonuçlarına ulaşmışlardır. Öte yandan Bianchi ve Phillips [3] ile Van Deursen ve arkadaşları [7] çalışmalarında genç yaştaki katılımcıların akıllı telefon kullanımlarının daha fazla olduğunu ileri sürerken, Ünal [33], Kuyucu [19] ve Mert ve Özdemir [25] yaşın akıllı telefon kullanımı üzerinde herhangi bir artırıcı veya azaltıcı etkisi olmadığını belirtmiştir. Bununla birlikte, Kuyucu [19] gelirin akıllı telefon kullanımında etkili olmadığını belirtirken Munasinghe [26] aile gelirinin artmasinın akıllı telefon kullanımını artırdığını tespit etmiştir. Son olarak, Kwon ve arkadaşları [18] kişilerin eğitim seviyesi arttıkça akıllı telefon kullanımının arttığını belirtirken, Mert ve Özdemir [25] kişilerin akıllı telefon kullanımında eğitim seviyelerine bağlı herhangi bir farkl1lık bulunmadığ sonucuna ulaşmıştır.

$\mathrm{Bu}$ çalışma, akıllı telefonların telefonla konuşma amacı dışındaki (ikincil amaçlar için) kullanımını ve akıllı telefon bağımlılığını etkileyen sosyoekonomik faktörleri ortaya çıkararak literatüre katkı yapmayı amaçlamaktadır.

\section{VERİ VE YÖNTEM (DATA AND METHOD)}

$\mathrm{Bu}$ çalışmada akıllı telefonların ikincil kullanımına ve akıllı telefon bağımlılığına etki eden sosyoekonomik etmenler incelenmiştir. Söz konusu incelemelerde, akıllı telefonların kullanımı (i) akıllı telefonun kullanım süresi ve (ii) akıllı telefon bağımlılık ölçeği [6] olmak üzere iki farkl gösterge ile ölçülmüştür.

Çalışma kapsamında toplam 144 gönüllü katılımcıya 15 Nisan - 15 Haziran 2019 tarihleri arasında sosyal, demografik ve ekonomik bilgilerini sorgulayan bir anket uygulanmış ve ardından beş hafta boyunca akıllı telefon kullanımını gösteren ekran görüntülerini iletmesi istenmiştir.

Akıllı telefon kullanım süresini izleme özelliğinin sadece Apple marka akıllı telefonlarda olması dolayısıyla söz konusu çalışma sadece Apple marka akıllı telefon kullanıcıları ile gerçekleştirilmiştir.

Apple marka akıllı telefon kullanıcılarından alınan ekran görüntülerinden kişilerin akıllı telefon kullanım süreleri elde edilmiş ve ekonometrik yazılım aracılığılyla veri setine birimi dakika olacak şekilde işlenmiştir. Kişiden (ekran görüntüleri aracılığıyla) beş hafta boyunca temin edilen akıllı kullanım sürelerinin ortalaması ilgili kişinin akıllı telefon kullanım süresi olarak tayin edilmiştir.

Apple marka akıllı telefonlar ekran süresi özelliği ile cihazın ne kadar kullanıldığı, açılan uygulamalar ve ziyaret edilen web siteleri ile ilgili ayrıntılı bir rapor elde etmeyi mümkün kılmaktadır. Bu yazılım, konuşma süreleri ile mobil uygulamaların kullanım sürelerini ayrı ayrı kaydetme özelliğine sahiptir. Çalışma kapsamında kişilerden alınan ve kişilerin akıllı telefon kullanımların gösteren ekran görüntülerinde telefonla konuşma amacıyla sarf edilen süre göz ardı edilmiş ve konuşma amacı dışındaki amaçlar için harcanan toplam süre dikkate alınmıştır. Bir başka deyişle çalışma kapsamında kullanılan akıllı telefon kullanım süreleri, telefonla konuşma amacıyla sarf edilen süreden arındırılmıştır.

Öte yandan, kişiye uygulanan ankette kişinin akı1llı telefonunu kendisi dişında kimlerin (eşi, çocuğu vb.) ne kadar ve hangi sıklıkla kullandığı tespit edilmiş ve ilgili kullanımlar da akıllı telefonun kullanım süresinden arındırılmıştır. Diğer bir ifade ile, kişiye tayin edilen akıllı telefon kullanım süresi kişinin sadece kendisinin akıllı telefonunu kullandığı süredir.

Çalışmanın bulgularının güçlülüğünü sınamak amacıyla ekran görüntüsü alınan kişilere bir de Kwon ve arkadaşları [18] tarafından geliştirilen Demirci ve ark. [6] tarafından Türkçe 'ye uyarlanan akıllı telefon kullanım ölçeği uygulanmıştır. Söz konusu ölçek 33 maddeden oluşmaktadır. Her maddeye ait görüşler 6'lı Likert ile kodlanmış; 6 "Kesinlikle Evet", 1 ise "Kesinlikle Hayır" seçeneğini temsil etmiştir. Ölçek puanları toplamda minimum 33 maksimum 198 puan değeri almaktadır ve ölçeğe göre puanın yüksek olması akıllı telefon bağımlılığının şiddetini göstermektedir. Akıllı telefon bağımlılığının tolerans, uzaklaşım, günlük yaşam bozukluğu, sanal ilişkiler, aşırı kullanım ve olumlu beklenti olmak üzere 6 faktör ile açıklanabileceği Kwon ve arkadaşları [18] tarafından gerçekleştirilen çalışmada belirtilmiştir.

Çalışmaya katılacak gönüllülerin seçimi kartopu yöntemi ile gerçekleştirilmiştir. Şöyle ki; çalışmaya katılmaya gönüllü olan bir kişiden bir tanıdığını önermesi istenmiştir. Çalışmaya katılacak kişilerin belirlenmesi ve/veya davet edilmesi aşamalarında akıllı telefon kullanılmamıştır. Kişilerin seçilmesi ve/veya davet edilmesi aşamalarında araç olarak akıllı telefonların kullanılmasının akıllı telefon bağımlılı̆̆ olan bireylerin örneklemde daha fazla yer almasına ve akıllı telefon bağımlılı̆̆ 1 olmayan bireylerin örneklemde daha az yer bulmasına veya hiç yer bulamamasına neden olacağına inanılmaktadır. Çalışmanın konusunun akıllı telefon bağımlılığı olması göz önünde bulundurulduğunda söz konusu durumun çalışmanın bulgularının yanlı olmasına yol açacağı düşünülmektedir. Dolayısıyla çalışma kapsamında olası yanlılıkları önlemek amacıyla çalışmaya katılacak kişilerin belirlenmesi ve/veya davet edilmesi akıllı telefon kullanılmadan gerçekleştirilmiştir. Diğer bir deyişle çalışmaya katılmaya gönüllü olan kişi akıllı telefon kullanmadan ulaşabileceği (yüz yüze vb.) bir kişiyi önermiş ve davetliye akıllı telefon kullanılmadan ulaşılmıştır.

Çalışmada akıllı telefon kullanımına etki eden sosyoekonomik faktörleri saptamak amaciyla lineer regresyon yöntemi kullanılmıştır. Sosyoekonomik faktörlerden oluşan bir model oluşturulmuş ve akıllı telefon kullanımının iki göstergesi olan (i) akıllı telefon kullanım süresi ile (ii) akıllı telefon bağımlılık skoru üzerinde ayrı ayrı uygulanmıştır. Söz konusu işlemi 
aşağıdaki formül aracılığıyla ekonometrik olarak ifade etmek mümkündür.

$$
y=\alpha+\sum_{k} \beta_{k} X_{k}+u
$$

Formülde $y$ sırasıyla akıllı telefon kullanım süresi ile akıllı telefon bağımlılık skorunu, $\alpha$ sabit değeri, $X_{k}$ k sayıdaki sosyoekonomik faktörü, $\beta_{k} \mathrm{k}$ sayıdaki sosyoekonomik faktörün sırasıyla akıllı telefon kullanım süresi ile akıllı telefon bağımlılık skoru üzerindeki etkilerini ve $\mathrm{u}$ ise model tarafindan tahmin edilemeyen etkileri ifade etmektedir.

Çalışma kapsamında kişinin yaşının, cinsiyetinin, medeni halinin, eğitim seviyesinin, gelir durumunun, çalışma durumunun ve toplu taşıma kullanma durumunun akıllı telefon kullanımına etkileri araştırılmıştır. Kişinin yaşı sürekli değişken olarak; cinsiyeti, çalışma durumu ve toplu taşıma durumu ise birer kukla değişken olarak modelde yer almıştır. Kişi sayısının az olması dolayısıyla evli olanlar bir kategoride, bekar veya boşanmış gibi evli olmayan kişiler ise bir başka kategoride toplanmıştır. Evli olmayanlar kategorisi referans kategori olarak kararlaştırılmıştır. Eğitim seviyesi üç farklı kategori ile temsil edilmektedir. İlk kategori üniversiteden daha düşük eğitim seviyesine sahip olanları, ikinci kategori üniversite mezunlarını ve üçüncü kategori ise üniversiteden daha yüksek bir eğitim seviyesine sahip olanları barındırmaktadır. Analizlerde üniversite mezunları referans kategori olarak kabul edilmiştir. Kişilerin gelir durumu, ailelerinin aylık toplam gelirlerini ifade etmektedir ve dört kategoriye ayrılmıştır. İlk kategori az gelir seviyesini (aylık 0 TL - 3500 TL), ikinci kategori az-orta gelir seviyesini (aylık 3501 TL 5000 TL), üçüncü kategori orta-çok gelir seviyesini (aylık $5001 \mathrm{TL}-8000 \mathrm{TL}$ ) ve son kategori çok gelir seviyesini (8001 TL ve üzeri) temsil etmektedir. Analizlerde çok gelir kategorisi referans kategori olarak tayin edilmiştir.

Modelde yer alan bağımlı ve bağımsız değişkenlerin özet istatistiki bilgileri aşağıda Tablo 1'de sunulmuştur. Buna göre çalışmaya katılan kişilerin \%34'ü erkek ve \%66's1 kadındır. Bu kişilerin yaş ortalaması 28 iken \%41'i evli, $\% 59$ 'u ise ya hiç evlenmemiş ya da evlenip boşanmış durumundadır. Yine bu kişilerin yaklaşık \%58'i çalışıyorken \%42'si herhangi bir işte aktif olarak çalışmamakta, yaklaşık \%57'si ulaşım için sürekli toplu taşımayı kullanırken yaklaşık \%43'ü toplu taşımayı sürekli olarak kullanmamaktadır. Çalışmaya katılan 144 kişinin yaklaşık \%21'i üniversiteden daha düşük bir eğitim seviyesine sahipken, \%62'si üniversite mezunu, yaklaşık $\% 17$ 'si ise üniversiteden daha yüksek bir eğitim seviyesine sahiptir. Bu kişilerin \%18'inin aylık aile geliri 3500 Türk Lirasından (TL) az iken, yaklaşı $\% 28$ 'inin aylık aile geliri 3501 TL ile 5000 TL arasında, \%26'sının aylık aile geliri 5001 TL ile 8000 TL arasında, yaklaşık \%28'inin aylık aile geliri ise $8001 \mathrm{TL}$ veya daha fazladır. Bu kişilerin akıllı telefonlarını ikincil amaçlar için (telefonla konuşmak dışındaki amaçlar için) kullanma süresi ortalama 211 dakika (bir başka deyişle yaklaşık üç buçuk saat); akıllı telefon bağımlılığı ortalama skoru ise yaklaşık $77^{\prime}$ dir.

Tablo 1. Modellerde kullanılan değişkenlere ait özet istatistiki bilgiler (Summary statistics of the variables used in the models)

\begin{tabular}{|c|c|c|c|c|c|}
\hline Değişken Adı & Açıklama & $\begin{array}{c}\text { Kişi } \\
\text { Sayısı }\end{array}$ & Ort. & Min. & Max. \\
\hline $\begin{array}{l}\text { ORTALAMA } \\
\text { SÜRE }\end{array}$ & $\begin{array}{l}\text { Kişinin günde ortalama akıllı telefon kullanım süresi } \\
(=\text { Dakika })\end{array}$ & 144 & 211,458 & 0 & 469 \\
\hline SKOR & Kişinin akıllı telefon bağımlılık skoru & 144 & 76,764 & 34 & 149 \\
\hline YAŞ & Kişinin Yaşı & 144 & 28,181 & 18 & 56 \\
\hline ERKEK & Kişinin Cinsiyeti $=$ Erkek & 144 & 0,340 & 0 & 1 \\
\hline EVLI & Kişinin Medeni Hali $=E v l i$ & 144 & 0,417 & 0 & 1 \\
\hline EĞİTİM1 & $\begin{array}{l}\text { Kişinin Eğitim Durumu = Üniversiteden Daha Düşük Bir Eğitim } \\
\text { Seviyesi }\end{array}$ & 144 & 0,208 & 0 & 1 \\
\hline EĞİTİM2 & Kişinin Eğitim Durumu = Üniversite & 144 & 0,625 & 0 & 1 \\
\hline EĞİTİM3 & Kişinin Eğitim Durumu = Üniversiteden Daha Çok Bir Eğitim Seviyesi & 144 & 0,167 & 0 & 1 \\
\hline GELIR1 & Kişinin Gelir Durumu $=A z$ Gelir Seviyesi & 144 & 0,181 & 0 & 1 \\
\hline GELİR2 & Kişinin Gelir Durumu $=A z-$ Orta Seviye Gelir & 144 & 0,278 & 0 & 1 \\
\hline GELİR3 & Kişinin Gelir Durumu $=$ Orta - Çok Seviye Gelir & 144 & 0,264 & 0 & 1 \\
\hline GELİR4 & Kişinin Gelir Durumu $=$ Çok Gelir Seviyesi & 144 & 0,278 & 0 & 1 \\
\hline ÇALIŞAN & Kişinin Çalışma Durumu $=$ Çalışıyor & 144 & 0,576 & 0 & 1 \\
\hline TOPLU TAŞIMA & Toplu Taşıma Kullanma Durumu $=$ Kullanıyor & 144 & 0,569 & 0 & 1 \\
\hline
\end{tabular}

\section{BULGULAR (RESULTS)}

Çalışma kapsamında uygulanan regresyonların sonuçları aşağıda Tablo 2'de sunulmuştur. Söz konusu tabloda ilk sütun modele dahil edilen bağımsız değişkenleri, ikinci ve üçüncü sütunlar ise sırasıyla akıllı telefon kullanım süresi ve akıllı telefon bağımlılık skoru için gerçekleştirilen tahminleri göstermektedir.
Tablo 2'de her bir bağımsız değişkenin karşısında iki satır bulunmaktadır. Üstteki satır ilgili değişkenin bağımlı değişken (bu çalışma için akıllı telefon kullanım süresi veya akıllı telefon bağımlılık skoru) üzerindeki etkisini $\left(\beta_{k}\right)$, alttaki satır ise standart hatayı göstermektedir. 
Buna göre, bazı tahminler istatistiksel anlamlılığını yitirse de sonuçlar genel itibariyle birbiri ile uyumluluk göstermektedir. Kişinin yaşı arttıkça akıllı telefon bağımlılık skoru düşmektedir. Yaşın istatistiksel olarak anlamlı bir etkisi gözükse de, ortalama akıllı telefon bağımlılık skorunun yaklaşık 77 olduğu göz önünde bulundurulursa elde edilen etki önemsenmeyecek seviyededir. Akıllı telefonları kullanma alışkanlıkları ve ilerleyen yaştakilerin akıllı telefonla daha geç tanışmaları dolayısıyla akıllı telefonlara uyum sağlayamamaları ve daha sinırlı amaçlar için kullanabilmeleri hesaba katıldığında kişinin yaşının daha belirgin bir etkisinin olması beklenmektedir. Ancak şaşırtıcı bir şekilde, kişinin yaşının beklenen etkisi hem akıllı telefon kullanım süresi için hem de akıllı telefon bağımlılı skoru için görülememektedir. Halbuki, aşağıda Şekil 1'de görüleceği üzere ileri yaşlarda kişilerin akıllı telefon kullanım süreleri aşağ1 doğru eğim göstermektedir. Örneklemdeki kişi sayısının az olmasının söz konusu etkinin görülememesinde rol oynamış olabileceği düşünülmektedir. Araştırmaya katılacak kişi sayısının artırılması yaş ile akıllı telefon kullanım süresi arasındaki ilişkinin eğimini anlamlı bir şekilde ortaya çıkarmaya katkı sağlayacaktır. Dolayısıyla yaş ile alakalı bulunan sonuç bu şekli ile Bianchi ve Phillips [3]'in ve Van Deursen ve arkadaşlarının [7] aleyhine, Ünal [33]'1, Kuyucu [19]'yu ve Mert ve Özdemir [25]'i destekler niteliktedir.

Tablo 2'de görüldüğü üzere erkekler, kadınlara kıyasla daha uzun süre (yaklaşık 68 dakika daha fazla) akıllı telefon kullanmaktadır. Erkekler ve kadınlar arası benzeri bir farklılık akıllı telefon bağımlılık skoru için de söylenebilir ancak söz konusu farklılı̆̆ın istatistiksel olarak sıfırdan farkı bulunmamaktadır. $\mathrm{Bu}$ sonuç, literatürde kadın ve erkek arasında herhangi bir akıllı telefon kullanım farklılığı olmadığını öne süren Kwon ve arkadaşları [18], Ünal [33], Kuyucu [19], Mert ve Özdemir [25] aksine kadınlar ile erkekler arasında belirgin bir akıllı telefon kullanım süresi farkını ortaya koymaktadır. Bununla birlikte, söz konusu sonuç kadınların daha fazla akıllı telefon kullandığını belirten çalışmaların (Junco ve arkadaşları [14], Randler ve arkadaşları [28], Kim ve arkadaşları [17]) tersini ileri sürmekte ve Aljooma ve arkadaşları [2] gibi erkeklerin kadınlara kıyasla daha uzun süre akıllı telefon kullandığını göstermektedir.

Öte yandan, evli bireyler evli olmayanlara kıyasla hem daha kısa süre (yaklaşık 56 dakika daha az) akıllı telefon kullanmakta hem de daha az akıllı telefon bağımlılık skorlarına sahiptir. Akıllı telefon kullanım sürelerinin kişinin sadece kendi kullanımı olduğunu (eşinin ve/veya çocuğunun kullanımından arındırıldığını) ve evli bireylerin evlilik rollerinin olduğu (eşiyle zaman geçirmesi, beraber programlar düzenlemesi vb.) hesaba katılırsa medeni durumun söz konusu etkileri beklenen etkilerdir.

Kişilerin eğitim seviyesi ile alakalı beklenen etki ne yazık ki gerçekleştirilen tahminlerde tam anlamıyla elde edilememiştir. Sadece, üniversite mezunları ile üniversiteden daha düşük bir eğitim seviyesine sahip insanların akıllı telefon kullanım süreleri arasında anlamlı bir fark tespit edilmiştir. Buna göre üniversite mezunlar1, kendilerinden daha düşük eğitim seviyesine sahip insanlara kıyasla ortalamada yaklaşık 31 dakika daha fazla akıllı telefon kullanmaktadır. Söz konusu farklılığın üniversite mezunlarının akıllı telefonlarını daha işlevsel kullanmalarından kaynaklanıyor olabileceği düşünülmektedir. Bu sonuç Mert ve Özdemir [25]'in aleyhine Kwon ve arkadaşlarını [18] destekler niteliktedir.

Kişilerin aylık toplam aile gelirinin akıllı telefon kullanımı süresine etkisi istatistiksel olarak anlamlı olmasa da, söz konusu etkiler akıllı telefon bağımlılı̆̆ı skoruna olan etkiler ile uyum içerisindedir. Buna göre, çok gelirli aileler tüm gelir kategorilerine kıyasla daha uzun akıllı telefon kullanım sürelerine ve akıllı telefon bağımlılık skorlarına sahiptirler. Bu açıdan çalışmanın bulgularının Munasinghe [26] ile aynı doğrultuda olduğunu söylemek mümkündür.

Tablo 2. Akıllı telefon kullanımı için yapılan regresyon sonuçları

(Regression results for smartphone use)

\begin{tabular}{|c|c|c|}
\hline & $\begin{array}{c}\text { AKILLI } \\
\text { TELEFON } \\
\text { KULLANIM } \\
\text { SÜRESİ }\end{array}$ & $\begin{array}{c}\text { AKILLI } \\
\text { TELEFON } \\
\text { BAĞIMLILIK } \\
\text { SKORU }\end{array}$ \\
\hline \multirow{2}{*}{ YAŞ } & $-0,982$ & $-0,427 *$ \\
\hline & 1,512 & 0,244 \\
\hline \multirow{2}{*}{ ERKEK } & $67,644 * * *$ & 2,826 \\
\hline & 21,337 & 3,742 \\
\hline \multirow{2}{*}{ EVLI } & $-55,612 * *$ & $-7,67 * *$ \\
\hline & 24,756 & 3,86 \\
\hline \multirow{2}{*}{ EĞíTİM1 } & $-31,435^{*}$ & 5,422 \\
\hline & 33,715 & 4,95 \\
\hline \multirow{2}{*}{ EĞİTİM3 } & $-53,372$ & $-1,28$ \\
\hline & 27,95 & 4,421 \\
\hline \multirow{2}{*}{ GELİR1 } & $-19,415$ & $-12,121 * *$ \\
\hline & 33,062 & 4,999 \\
\hline \multirow{2}{*}{ GELİR2 } & $-9,333$ & $-12,836 * *$ \\
\hline & 31,294 & 5,314 \\
\hline \multirow{2}{*}{ GELİR3 } & $-48,606$ & $-11,199 * *$ \\
\hline & 29,93 & 4,731 \\
\hline \multirow{2}{*}{ ÇALIŞAN } & 3,744 & $-1,562$ \\
\hline & 24,16 & 3,691 \\
\hline \multirow{2}{*}{$\begin{array}{l}\text { TOPLU } \\
\text { TAŞIMA }\end{array}$} & 0,333 & 0,736 \\
\hline & 25,1 & 4,065 \\
\hline \multirow[t]{2}{*}{ SABİT } & $271,329 * * *$ & $99,333 * * *$ \\
\hline & 46,53 & 7,154 \\
\hline
\end{tabular}

Bunlarla birlikte, beklenmedik bir şekilde, çalışma durumu ve toplu taşıma kullanma durumunun akıllı telefon kullanımı üzerinde herhangi bir etkisi bulunamamıştır. Çalışanların çalışmayanlar ile, toplu taşıma kullananların da kullanmayanlar ile benzer akıllı telefon kullanma alışkanlıklarının olmasının (birbirine yakın akıllı telefon kullanma süreleri gibi) ilgili faktörler için herhangi bir etki 
gözlenememesine sebebiyet vermiş olabileceği düşünülmektedir. Söz konusu kategorilerdeki bireylerin akıllı telefon kullanımı süreleri ile akıllı telefon kullanımı skorlarının ortalamalarını aşağıda Tablo 3'te görmek mümkündür.

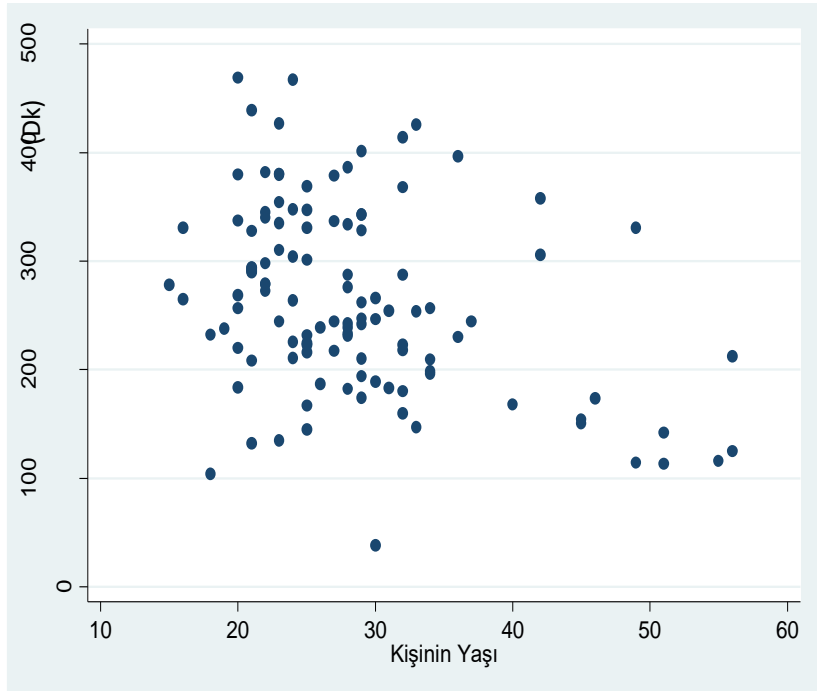

Şekil 1. Kişilerin yaşları ile akıllı telefon kullanım sürelerine göre dağılımı

(Distribution of individuals by age and duration of smartphone use)

Tablo 3. Çalışma durumu ve toplu taşıma kullanma durumuna göre ortalama akıllı telefon kullanım süreleri ve skorlar1

(The durations and the scores of smartphone use according to employment status and public transport usage)

\begin{tabular}{|l|c|c|}
\hline & $\begin{array}{c}\text { Akıllı } \\
\text { Telefon } \\
\text { Kullanım } \\
\text { Süresi }\end{array}$ & $\begin{array}{c}\text { Akıllı } \\
\text { Telefon } \\
\text { Kullanım } \\
\text { Skoru }\end{array}$ \\
\hline Çalışanlar & 215,33 & 75,22 \\
\hline Çalışmayanlar & 206,18 & 78,85 \\
\hline $\begin{array}{l}\text { Toplu Taşıma } \\
\text { Kullananlar }\end{array}$ & 216,43 & 77,24 \\
\hline $\begin{array}{l}\text { Toplu Taşıma } \\
\text { Kullanmayanlar }\end{array}$ & 204,87 & 76,12 \\
\hline
\end{tabular}

\section{SONUÇ (CONCLUSION)}

Bu çalışmada akıllı telefon kullanımına ve akıllı telefon bağımlılığına etki eden sosyoekonomik faktörler araştırılmıştır. Türkiye'de akıllı telefon kullanımının dünya ortalamasının önemli ölçüde üzerinde olduğu hesaba katılırsa [37], Türkiye'de akıllı telefon kullanımına etki eden sosyoekonomik faktörlerin ortaya çıkartılması oldukça önem arz etmektedir. Söz konusu faktörlerin tespit edilmesi Türkiye'de akıllı telefonların fazla kullanımından kaynaklanan sorunların önüne geçmeye katkı sağlayacaktır.

Bu çalışmada dikkat edilmesi gereken husus çalışmanın odağının akıllı telefonların birincil amaç (telefonla sesli arama gerçekleştirmek) için kullanımından daha çok akıllı telefonların ikincil amaç için kullanımlarına yönelik olduğudur. Dolayısıyla bu çalışma akıllı telefonların telefonla konuşma dışındaki işlevleri için kullanılmasına ve akıllı telefon bağımlılığına etki eden sosyoekonomik faktörleri ortaya çıkarmayı amaçlamaktadır. Çalışmanın literatüre önemli katkılarından biri de toplam 144 gönüllü katılımcıdan beş hafta boyunca alınan ve akıllı telefonların kendilerince depolanan akıllı telefon kullanım süresi verileri ile gerçekleştirilmiş olmasıdır.

Çalışmanın bulgularının güçlülüğünü sınamak amacıyla akıllı telefon kullanımı, akıllı telefon kullanım süresinin yanı sıra Kwon ve arkadaşları [18] tarafından geliştirilen, Demirci ve ark. [6] tarafından Türkçe' ye uyarlanan akıllı telefon bağımlılığı ölçeği ile de ölçülmüştür.

Sosyoekonomik faktörlerin akıllı telefon kullanımı üzerindeki etkileri çok değişkenli (lineer) regresyon yöntemi ile tespit edilmiştir. Dolayısıyla, çalışma kapsamında sosyoekonomik faktörlerden oluşan ekonometrik bir model oluşturulmuş ve bu model akıllı telefon kullanımının iki göstergesi olan (i) akıllı telefon kullanım süresi ile (ii) akıllı telefon bağımlılık skoru için uygulanmıştır. Söz konusu tahminlerde bazı faktörlerin etkileri istatistiki anlamlılık bakımından eksik olmasına rağmen, iki farklı gösterge için oluşturulan tahmin değerleri birbiri ile uyumluluk göstermektedir.

Buna göre kişinin cinsiyeti, medeni hali, eğitim seviyesi ve gelir seviyesi kişinin akıllı telefon kullanım alışkanlığ üzerine önemli bir etkiye sahiptir. Erkeklerin ve kadınların akıllı telefon kullanım alışkanlıkları arasında ciddi farklılıklar bulunmuştur. Şöyle ki, erkekler kadınlara kıyasla önemli ölçüde daha fazla akıllı telefon kullanmaktadır. Erkeklerin ve kadınların akıllı telefon kullanım amaçlarını araştıracak ileri çalışmaların söz konusu farklılığı açıklamada katkıda bulunacağına inanılmaktadır.

Bununla birlikte, evli olan bireyler ile evli olmayan bireyler arasında yine önemli farklılıklar bulunmaktadır. Evli olan bireyler evli olmayan bireylere kiyasla daha düşük akıllı telefon kullanıma sahiptirler. Evli olan bireylerin, evlilik ve/veya ebeveyn rollerinin söz konusu farklılığa sebep olduğu düşünülmektedir.

Öte yandan üniversite mezunları, kendilerinden daha düşük eğitim seviyesine sahip insanlara kıyasla daha fazla akıllı telefon kullanmaktadır. Üniversite mezunlarının akıllı telefonlarını daha işlevsel kullanmaları ihtimali söz konusu farklılığın saptanmasına açıklık getirebilir. Son 
olarak, kişilerin gelirine yönelik en belirgin tespit çok gelirli bireyler ile diğer gelir kategorileri arasındadır. Buna göre, en yüksek gelir grubundaki bireyler kendilerinden daha düşük gelir gruplarındaki bireylere kıyasla daha yüksek akıllı telefon kullanım sürelerine ve bağımlılık skorlarına sahiptirler. Bu bağlamda farklı eğitim ve gelir gruplarının akıllı telefon kullanma amaçlarının ve akıllı telefonlarını ne kadar işlevsel kullandıklarının araştırılması literatüre katkı sağlayacaktır.

Bunlara karşılık, kişinin yaşının (istatistiksel olarak anlamlı olmasına rağmen), çalışma durumunun ve toplu taşıma kullanma durumunun akıllı telefon kullanım alışkanlığı üzerinde belirgin bir etkisi bulunmamaktadır. Çalışmaya katılan kişi sayısının artırılmasının bu faktörler ile akıllı telefon kullanımı arasında hem etki büyüklüğünde hem de istatistiksel büyüklükte anlamlı ilişkiler gözlenmesine katkı sağlayacağına inanılmaktadır.

\section{KAYNAKÇA (REFERENCES)}

[1] A. A. Alhassan., E. M. Alqadhib, W. N. Taha, R. A. Alahmari, M Salam, A. F. Almutairi, "The Relationship Between Addiction To Smartphone Usage And Depression Among Adults: A Cross Sectional Study”, BMC Psychiatry, 18(148), 1-8, 2018.

[2] S. S. Aljomaa, M. F. A. Qudah, I. S. Albursan,S. F. Bakhiet, A. S. Abduljabbar, "Smartphone Addiction Among University Students in the Light of Some Variables", Computers in Human Behavior 61, 155-164, 2016.

[3] A. Bianchi, G. J. Phillips, "Psychological predictors of problem mobile phone use", CyberPsychology \& Behavior, 8(1), 39-51, 2005.

[4] G. F. Brunborg, R. A. Mentzoni, Moldeh., H. Myrseth, K. J. M. Skouverøe, B. Bjorvatn, S. Pallesen, "The relationship between media use in the bedroom, sleep habits and symptoms of insomnia", Journal of Sleep Research (J Sleep Res), 20(4), 569575,2011 .

[5] K. Demirci, M. Akgönül, A. Akpınar, "Relationship of smartphone use severity with sleep quality, depression, and anxiety in university students", Journal of Behavioral Addictions, 4(2), 85$92,2015$.

[6] K. Demirci, H. Orhan, A. Demirdas, A. Akpinar, H. Sert, "Validity and Reliability of the Turkish Version of the Smartphone Addiction Scale in a Younger Population", Klinik Psikofarmakoloji Bülteni, 24(3), 226-233, 2014.

[7] A. J. A. M. V. Deursen, C. L. Bolle, S. M. Hegner, P. A. M. Kommers, "Modeling habitual and addictive smartphone behavior The role of smartphone usage types, emotional intelligence, social stress, self-regulation, age, and gender", Computers in Human Behavior, 45, 411-420, 2015.

[8] É. Duke, C. Montag, Smartphone Addiction, Daily Interruptions And Self-Reported Productivity, Addictive Behaviors Reports 6, 90-95, 2017.

[9] J. Y. Kim, The Changing Nature of Work, World Bank Group, USA, 2019.

[10] Cep Telefonu Kullanımı: Sürücü Dikkat Dağınıklığında Giderek Büyüyen Bir Sorun, Emniyet Genel Müdürlüğü, 680, Ankara, 2017.
[11] H. Fidan, "Mobil Bağımlılık Ölçeği'nin Geliştirilmesi Ve Geçerliliği: Bileşenler Modeli Yaklaşımı”, Addicta: The Turkish Journal On Addictions, 3(3), 433-469, 2016.

[12] E. E. İnal, K. Demirci, A. Çetintürk, M. Akgönül, S. Savaş, "Effects of Smartphone Overuse on Hand Function, Pinch Strength, And The Median Nerve", Muscle \& Nerve, 52(2), 183$188,2015$.

[13] İnternet: https://support.apple.com/tr-tr/HT208982., 11.05.2020

[14] R. Junco, D. Merson, D. W. Salter, "The Effect of Gender, Ethnicity, and Income on College Students' Use of Communication Technologies", Cyberpsychology, Behavior, And Social Networking, 13(6), 619-627, 2010.

[15] H. J. Kim, J. S. Kim, "The relationship between smartphone use and subjective musculoskeletal symptoms and university students", Journal of Physical Therapy Science, 27: 575-579, 2015 .

[16] M. S. Kim, "Influence of neck pain on cervical movement in the sagittal plane during smartphone use", Journal of Physical Therapy Science, 27(1), 15-17, 2015.

[17] Y. Kim, J. E. Jeong, H. Cho, D. J. Jung, M. Kwak,M. J. Rho, H. Yu, D. J. Kim, I. Y. Choi, "Personality Factors Predicting Smartphone Addiction Predisposition: Behavioral Inhibition and Activation Systems, Impulsivity, and Self-Control", PLoS ONE 11(8), 1-15, 2016.

[18] M. Kwon., Y. J. Lee,, Y. W. Won, W. J. Park, A. J. Min, \& C. Hahn, "Development and validation of a smartphone addiction scale (SAS)", PLoS One, 8(2), 1-7, 2013.

[19] M. Kuyucu, "Gençlerde Akıllı Telefon Kullanımı Ve Akıllı Telefon Bağımlılığı Sorunsalı: ‘Akıllı Telefon (Kolik)' Üniversite Gençliği”, Global Media Journal TR Edition, 7(14),328-259, 2017.

[20] K. Lanaj, R. E. Johnson, C. M. Barnes, "Beginning the workday yet already depleted? Consequences of late-night smartphone use and sleep", Organisational Behavior and Human Decision Processes, 124, 11-23, 2014.

[21] S. Lee, H. Kang \& G. Shin, "Head flexion angle while using a smartphone", Journal Ergonomics, 58(2), 220-226, 2015.

[22] Y. S. Lee, H. S. Yang, C. J. Jeong, Y. D. Yoo, G. Y. Jeong, J. MoonS, M. K. Kang, S. W. Hong, "Changes in the Thickness of Median Nerves Due to Excessive Use of Smartphones", Journal of Physical Therapy Science, 24, 1259-1262, 2012.

[23] S. Lemola, N. P. Gloor, S. Brand, J. F. D. Kaufmann, A. Grob, “Adolescents' Electronic Media Use at Night, Sleep Disturbance, and Depressive Symptoms in the Smartphone", Age, Journal of Youth and Adolescence, 44, 405-418, 2015.

[24] L. Li, C. T. T. Lin, "Over-Connected? A Qualitative Exploration Of Smartphone Addiction Among Working Adults İn China”, Bmc Psychiatry, 19(186), 1-10, 2019.

[25] A. Mert, G. Özdemir, "Yalnızlık Duygusunun Ak1llı Telefon Bağımlılığına Etkisi”, Uluslararası Toplum Araştırmaları Dergisi, 8(8), 88-107, 2018.

[26] G. P. Munasinghe, "Factors influencing the Smartphone Addiction among Students of the North Central Province in Sri Lanka", Proceedings of Annual Bangkok Business and Social Sciences Research Conference, Bangkok-Thailand, 2016. 
[27] J. Park, J. Kim, J. Kim, K. Kim, N. Kim, I. Choi, S. Lee, J. Yim, "The effects of heavy smartphone use on the cervical angle, pain threshold of neck muscles and depression", Advanced Science and Technology Letters, 91(3), 12-17, 3-4, 2015.

[28] C. Randler, L. Wolfgang, K. Matt, E. Demırhan, M. B. Horzum, Ş. Beşoluk, "Smartphone addiction proneness in relation to sleep and morningness-eveningness in German adolescents", Journal of Behavioral Addictions, 5(3), 465-473, 2016.

[29] J. M. Shim, "The Effect of Carpal Tunnel Changes on Smartphone Users", Journal of Physical Therapy Science, 24(12), 1251-1253, 2012.

[30] S. R. Sok, M. H. Seong, H. M. Ryu, "Differences of Self-Control, Daily Life Stress, and Communication Skills between Smartphone Addiction Risk Group and General Group in Korean Nursing Students", Psychiatric Quarterly 90(1),1-9, 2019.

[31] S. Sussman, N. A. Sussman, "Considering the Definition of Addiction”, International Journal of Environmental Research and Public Health, 8(10), 4025-4038, 2011.

[32] T. Tan, A. Kuek, S. E. Goh, E. L. Lee, V. "Kwok, Internet and smartphone application usage in eating disorders: A descriptive study in Singapore", Asian Journal of Psychiatry, 19, 50-55, 2016.

[33] H. M. Ünal, Ankara Yıldırım Beyazıt Üniversitesi Tıp Fakültesi öğrencilerinin akılı telefon bağımlılık düzeylerinin belirlenmesi, Uzmanlık Tezi, Sağlık Bakanlığı Yıldırım Beyazıt Üniversitesi Tıp Fakültesi Aile Hekimliği Anabilim Dalı, Ankara, 2015 .
[34] Yeşilay, Türkiye Bağımlılıkla Mücadele Programı, Yetişkin, Kültür Sanat Basımevi, 2017.

[35] S. Yıldırım, A. N. Kişioğlu, "Teknolojinin Getirdiği Yeni Hastalıklar: Nomofobi, Netlessfobi, Fomo", Süleyman Demirel Üniversitesi Tip Fak. Dergisi, 25(4), 473-480, 2018.

[36] Ö. Ş. Yusufoğlu, "Boş Zaman Faaliyeti Olarak Akıllı Telefonlar Ve Sosyal Yaşam Üzerine Etkileri: Üniversite Öğrencileri Üzerine Bir Araştırma", Insan Ve Toplum Bilimleri Araştırmaları Dergisi, 6(5), 2414-2434, 2017.

[37] We Are Social, Digital in 2018, Essentral Insights Into Internet, Social Media, Mobile, And Ecommerce Use Around The World, 2018.

[38] X. Lu, J. Watanable, Q. Liu, M. Uji, M. Shono, T. Kitamura, "Internet and mobile phone text-messaging dependency: Factor structureand correlation with dysphoric mood among Japanese adults", Computers in Human Behavior, 27, 2011.

[39] A. A. Alhassan, E. M. Alqadhib, N. W. Taha, R. A. Alahmari, M. Salam, A. F. Almutairi, "The relationship between addiction to smartphone usage and depression among adults: a cross sectional study", BMC Psychiatry, 18(148), 1-8, 2018. 